Egyptian

Orthodontic Journal

\title{
EFFECT OF LOW LEVEL LASER ON ROOT RESORPTION WITH EN MASSE MAXILLARY ANTERIOR RETRACTION: A RANDOMIZED CLINICAL TRIAL
}

\author{
Tarek N. Yousry ${ }^{1}$, Nadia M. El-harouni ${ }^{2}$, Nagwa M. Enany ${ }^{2}$
} ABSTRACT:

The aim of this RCT is to study the effect of low level laser therapy $(\mathcal{L L L T})$ with en masse maxillary anterior retraction in class II division 1 female patients on root resorption. Materials and Methods: 20 non-growing female patients were randomly allocated in 2 groups: Group I receiving LLLT 4 times/month $(0,3,7$ and, 14) days of activation, Group II receiving no laser therapy. CBCT was taken at $\mathcal{T}_{1}$ (prior to retraction) and $\mathcal{T} 2$ (after closure of spaces). Root resorption was evaluated by analyzing both root length (RL) and root area (RA) of six anterior teeth and compared between $\tau_{1}$ and $T_{2}$. Results: Root resorption was detected in all teeth in both groups with significant difference between the two groups regarding $R \mathcal{L}$ and $R A(P<0.01) \cdot \mathcal{N}$ o significant difference recorded between the percentage change in $R \mathcal{L}$ and $R A$ in both groups. Conclusion: Low-level laser therapy had no effect whether directly or indirectly on amount of apical root resorption during in masse retraction.

\section{INTRODUCTION}

Currently, fixed orthodontic treatment requires a long duration ranging from 2 to 3 years. ${ }^{(1)}$ This prolonged treatment period increases the risk of caries susceptibility, ${ }^{(2)}$ external root resorption, ${ }^{(3)}$ and decreased patient compliance. ${ }^{(4)}$ Thus, accelerating the rate of orthodontic tooth movement and subsequently shortening of the treatment duration will be quite beneficial.

1- Assistant Lecturer, Orthodontic Department, Alexandria University.

2- Professor, Orthodontic Department, Alexandria University. 
Egyptian

Orthodontic Journal

Multiple methods to accelerate tooth movement had been implemented including Corticotomies ${ }^{(5,6)}$, electric current ${ }^{(7)}$, electromagnetic field ${ }^{(8)}$ and prostaglandins injection. ${ }^{(9)}$

Use of lasers has become common in dentistry. Multiple studies evaluated the effect of laser therapy on rate of orthodontic tooth movement. Different results were reached. Stimulatory effect of low level laser therapy was reported by multiple studies. ${ }^{(10-18)}$ On the other hand, others $^{(19,20)}$ reported no significant effect of low level laser therapy on rate of tooth movement. Moreover, Seifi ${ }^{(21)}$ reported inhibitory effect of low level laser therapy on tooth movement.

External apical root resorption is a frequent iatrogenic outcome of orthodontic treatment. ${ }^{(22)}$ Many researches tried to identify the possible risk factors for development of root resorption with orthodontic treatment. These risk factors can be categorized into patient related factors and treatment related factors. Patient related factors include genetic predisposition, ${ }^{(23)}$ age,${ }^{(24)}$ gender ${ }^{(25)}$ tooth vitality, ${ }^{(26)}$ tooth type,${ }^{(24)}$ facial and dentoalveolar structure, ${ }^{(27)}$ pretreatment root resorption, ${ }^{(28)}$ and trauma ${ }^{(28)}$. Treatment related factors include magnitude of orthodontic force, ${ }^{(29)}$ treatment mechanics, ${ }^{(30)}$ direction of tooth movement, ${ }^{(31)}$ appliance type $^{(32)}$ and treatment duration. ${ }^{(33)}$

The required amount of tooth movement is a function of the severity of malocclusion, which makes the presence of severe malocclusion a risk factor for root resorption. ${ }^{(22)}$ Significant associations between EARR and the magnitude of overjet reduction during treatment have been found. ${ }^{(34)}$ Taner et al ${ }^{(35)}$ concluded in their study that Class II division 1 patients experienced significantly more root resorption than did class I patients, although no significant differences were found between the amount of root resorption and tooth inclination and duration of active treatment.

The null hypothesis of this clinical trial tested is that the low level laser therapy has no effect on the root resorption during en masse anterior retraction.

\section{MATERIALS AND METHODS}

Sample was selected from patients attending the outpatient clinic, orthodontic department, Alexandria University. This randomized controlled trial was approved by the ethical committee, Faculty of 
Egyptian

Orthodontic Journal

Dentistry (January 2012). The blind allocation was performed using the random sequence generator (www.random.org) to generate two columns of random sequence. Sample size calculation was made by the equation: $\mathrm{n}=\mathrm{f}(\alpha, \beta) \mathrm{X} 2 \mathrm{sd}^{2} /(\mu 1-\mu 2)^{2}$. Power of the study set at $80 \%$ and $\alpha$ of 0.05 . This yielded 11 subjects per arm i.e. 22 subjects in whole sample. Taking into considerations $10 \%$ sample attrition, the selected sample was set at 24 subjects.

The following criteria were strictly followed in patient selection. 1. Females with age range between 16 to 22 years. 2. Class II division 1 malocclusion with need of extraction of at least maxillary first premolars with need for maximum or absolute maxillary posterior anchorage. 3. Good oral hygiene and gingival condition with no loss of epithelial attachment. Patients with history of trauma, root canal treatment of anterior teeth and medically compromised were excluded from the study.

Twenty patients were chosen to be enrolled in the study. Only one failed to complete the study. Each patient and/or legal representative was informed orally and written of the risks and benefits of the enrollment in this study. Written signed informed consent form was collected from all patients before the onset of the study. The sample was randomly allocated into two equal groups. Group I: study group receiving low level laser therapy, Group II: control group. Both groups received the same sequence of treatment except for the application of low level laser therapy.

The patients were fitted with straight wire brackets 0.022 X 0.028 inch with Roth prescriptions. After initial leveling and alignment, $0.017 \mathrm{X} 0.025$ inch stainless steel wires were fitted for at least 4 weeks to ensure passivity of the wire. The site of the implant was chosen to be between the second premolar and first molar at the level of muco-ginigval junction. Retraction force was achieved by NiTi closed coil springs stretched between the crimpable hooks placed between lateral incisor and canine and directly connected to the mini-implant. Force was adjusted with a Correx tension gauge. The gauge was adjusted to produce $200 \mathrm{gm}$ of force per side. (Figure 1) The NiTi closed coil spring was activated every 28 days by re-activating the spring tension. 
The LLT equipment used in this study was a Gallium Aluminum Arsenide (Ga-Al-As) semiconductor diode laser, continuous radiation of wavelength $810 \mathrm{~nm}$ and power output $20 \mathrm{~mW}$. (Figure 2) The laser equipment was supplied by optic fiber with a tip of $2 \mathrm{~mm}$ in diameter and spectral area of $0.0314 \mathrm{~cm} 2$. Power density per point was $6.36 \mathrm{~W} / \mathrm{Cm} 2$. LLL was applied by contact method on selected points to cover the buccal and palatal mucosa of the anterior teeth; Two points on the cervical third (one medial and one distal), two on the apical third (one medial and one distal) and one on the middle third (on the center) of each involved tooth both buccally and palatally.( Figure 3) Low level laser was applied for 10 seconds per point to deliver an energy dose of $0.2 \mathrm{~J} /$ point. Energy dose per session was $8 \mathrm{~J} /$ session. Energy density per point was $6.36 \mathrm{~J} / \mathrm{cm} 2$. The application of low level laser was set at four times per month; following the onset of en-masse retraction; immediately after activation, 3 days after activation, 7 days after activation and 14 days after activation. The same protocol was repeated monthly till desired anterior retraction was achieved.

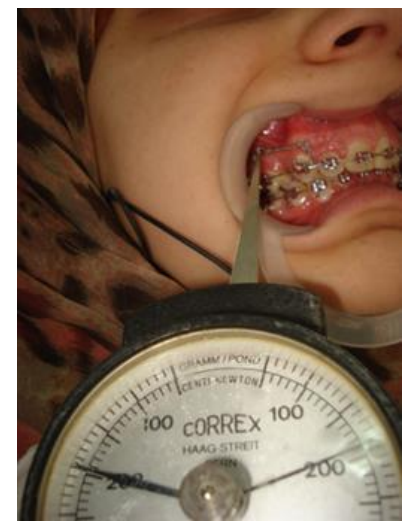

Figure 1: Force of retraction adjusted to $200 \mathrm{~g}$ per side

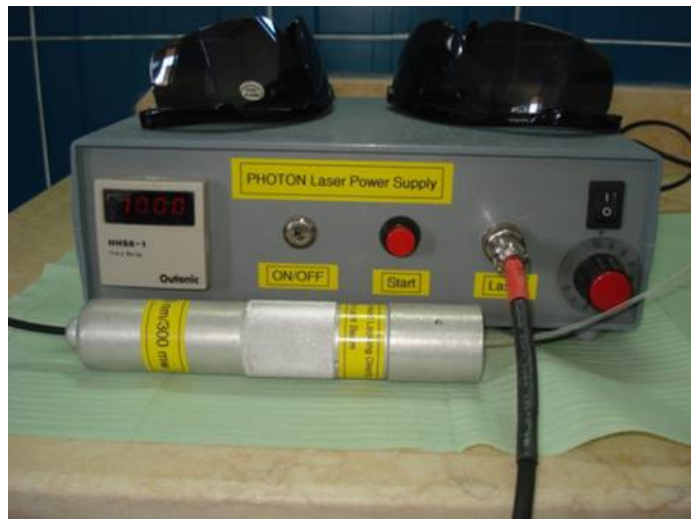

Figure 2: Laser apparatus used in study

Volume 48-December 2015 

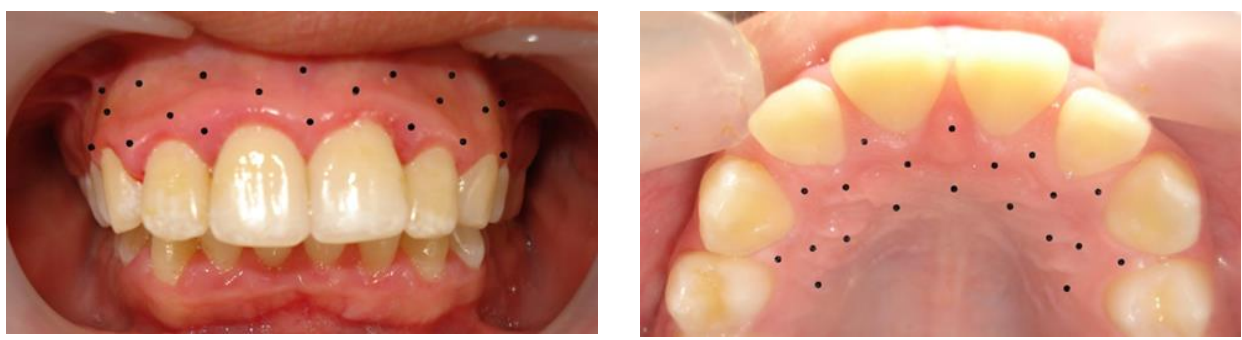

Figure 3: Graphical representation of points of laser application

Cone beam computed tomography (CBCT) was taken at two time intervals (Soredex Scanora 3D, medium FOV 75 X 100 with voxel size 0.2 $\mathrm{mm})$ : T1: Before the onset of en-masse retraction.T2: After the completion of en-masse retraction. The obtained data were analyzed by InVivo dental (Anatomage, San Jose, Calif). Three dimensional reconstructions were made with the use of the software. Prior to the measurement reorientation of the three planes were made with long axis of the tooth coinciding with the vertical plane. Measurements were made in the sagittal view. Reference plane was placed connecting the buccal and palatal cement-enamel junctions. The perpendicular distance was measured between the intersection of the long axis of the tooth and this reference plane and root apex (RL). (Figure 4).Area of the root surface (RA) between the reference plane and root contour was measured using the software.

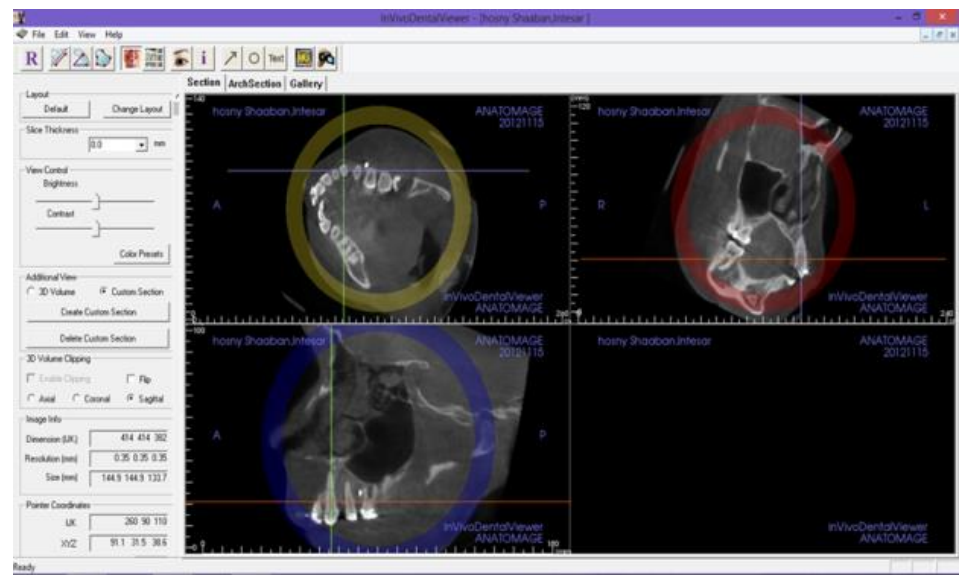

Figure 4: Orientation of the CBCT for measurement 
Egyptian

Orthodontic Journal

\section{RESULTS}

Tables I \& II show the change in root length and root area in laser group. Regarding RL, all teeth showed significant decrease in their measured root length post retraction with greater mean change in maxillary left lateral incisor followed by both canines and maxillary right lateral incisor. Regarding RA, greater mean change was for the maxillary left canine followed by maxillary left lateral incisor and maxillary right canine. Similarly all teeth showed significant root area decrease.

Tables III \& IV show the change in root length and root area in control group. The maxillary right showed the greater change in RL. All teeth showed significant root length decrease. Regarding RA, the greater change was also in maxillary right canine with all teeth showing significant decrease.

Tables V \&VI show the comparison between the difference in RL and RA between post retraction and pre retraction in both laser and control group. Significant difference existed in RL difference in UR1, UR2 and UR3. Similarly, significant difference existed in RA difference in all teeth between laser and control group.

Table I: Comparison between RL before and after retraction in laser group

\begin{tabular}{|l|c|c|c|}
\hline & $\begin{array}{c}\text { Pre } \\
\text { RL in } \mathbf{~ m m} \pm \text { SD }\end{array}$ & $\begin{array}{c}\text { Post } \\
\text { RL in } \mathbf{~ m m} \pm \text { SD }\end{array}$ & P \\
\hline UR1 & $12.57 \pm 1.05$ & $11.74 \pm 0.93$ & $0.008^{*}$ \\
\hline UR2 & $12.64 \pm 1.79$ & $11.57 \pm 1.54$ & $0.005^{*}$ \\
\hline UR3 & $17.05 \pm 1.89$ & $15.77 \pm 1.88$ & $0.005^{*}$ \\
\hline UL1 & $12.15 \pm 1.1$ & $11.26 \pm 0.99$ & $0.01^{*}$ \\
\hline UL2 & $13.29 \pm 2.63$ & $11.67 \pm 2.12$ & $0.013^{*}$ \\
\hline UL3 & $16.73 \pm 2.7$ & $15.42 \pm 2.29$ & $0.000^{*}$ \\
\hline
\end{tabular}

Volume 48 - December 2015 
Egyptian

Orthodontic Journal

Table II: Comparison between RA before and after retraction in laser group

\begin{tabular}{|l|c|c|c|}
\hline & $\begin{array}{c}\text { Pre } \\
\text { RA in mm2 } \pm \text { SD }\end{array}$ & $\begin{array}{c}\text { Post } \\
\text { RA in } \mathbf{~ m m 2 ~} \pm \text { SD }\end{array}$ & P \\
\hline UR1 & $52.97 \pm 7.15$ & $50.18 \pm 7.01$ & $0.002^{*}$ \\
\hline UR2 & $46.5 \pm 6.87$ & $43.96 \pm 6.91$ & $0.001^{*}$ \\
\hline UR3 & $73.26 \pm 10.19$ & $68.73 \pm 11.38$ & $0.006^{*}$ \\
\hline UL1 & $51.53 \pm 3.94$ & $48.85 \pm 4.12$ & $0.006^{*}$ \\
\hline UL2 & $51.03 \pm 12.92$ & $44.64 \pm 11.4$ & $0.009^{*}$ \\
\hline UL3 & $71.97 \pm 12.95$ & $64.97 \pm 10.75$ & $0.004^{*}$ \\
\hline
\end{tabular}

Table III: Comparison between RL before and after retraction in control group.

\begin{tabular}{|l|c|c|c|}
\hline & $\begin{array}{c}\text { Pre } \\
\text { RL in mm } \pm \text { SD }\end{array}$ & $\begin{array}{c}\text { Post } \\
\text { RL in mm } \mathbf{~ S D ~}\end{array}$ & P \\
\hline UR1 & $12.25 \pm 0.74$ & $11.09 \pm 1.69$ & $0.032^{*}$ \\
\hline UR2 & $12.96 \pm 1.05$ & $10.63 \pm 1.78$ & $0.01^{*}$ \\
\hline UR3 & $17.36 \pm 1.56$ & $15.04 \pm 1.8$ & $0.004^{*}$ \\
\hline UL1 & $12.07 \pm 1.49$ & $11.05 \pm 1.78$ & $0.006^{*}$ \\
\hline UL2 & $11.99 \pm 1.12$ & $10.79 \pm 1.45$ & $0.004^{*}$ \\
\hline UL3 & $16.31 \pm 1.38$ & $15.43 \pm 1.83$ & $0.02^{*}$ \\
\hline
\end{tabular}

Table IV: Comparison between RA before and after retraction in control group.

\begin{tabular}{|l|c|c|c|}
\hline & $\begin{array}{c}\text { Pre } \\
\text { RA in } \mathbf{~ m}^{2} \pm \text { SD }\end{array}$ & $\begin{array}{c}\text { Post } \\
\text { RA in } \mathbf{~ m m 2} \pm \text { SD }\end{array}$ & P \\
\hline UR1 & $50.98 \pm 4.61$ & $45.2 \pm 9.77$ & $0.03^{*}$ \\
\hline UR2 & $44.2 \pm 3.06$ & $38.21 \pm 4.91$ & $0.002^{*}$ \\
\hline UR3 & $73.24 \pm 11.16$ & $64.62 \pm 11.59$ & $0.009^{*}$ \\
\hline UL1 & $52.72 \pm 7.81$ & $47.91 \pm 9.68$ & $0.001^{*}$ \\
\hline UL2 & $44.64 \pm 5.11$ & $39.33 \pm 7.15$ & $0.009^{*}$ \\
\hline UL3 & $70.02 \pm 12.55$ & $64.22 \pm 12.05$ & $0.007^{*}$ \\
\hline
\end{tabular}


Table V: Comparison between the difference in RL in control and laser groups.

\begin{tabular}{|c|c|c|c|}
\hline & $\begin{array}{c}\text { Control } \\
\text { (RL difference in } \mathbf{~ m m})\end{array}$ & $\begin{array}{c}\text { Laser } \\
\text { (RL difference in } \mathbf{~ m m})\end{array}$ & P \\
\hline UR1 & -1.16 & -0.83 & $0.032^{*}$ \\
\hline UR2 & -2.33 & -1.07 & $0.017^{*}$ \\
\hline UR3 & -2.32 & -1.28 & $0.0331^{*}$ \\
\hline UL1 & -1.02 & -0.89 & 0.078 \\
\hline UL2 & -1.2 & -1.62 & 0.113 \\
\hline UL3 & -0.88 & -1.31 & 0.071 \\
\hline
\end{tabular}

Table VI: Comparison between the difference in RL in control and laser groups.

\begin{tabular}{|l|c|c|c|}
\hline & $\begin{array}{c}\text { Control } \\
\left(\text { RA difference in } \mathbf{~ m m}^{\mathbf{2}}\right)\end{array}$ & $\begin{array}{c}\text { Laser } \\
\left.\text { RA difference in } \mathbf{~ m m}^{\mathbf{2}}\right)\end{array}$ & P \\
\hline UR1 & -5.78 & -2.79 & $0.0036^{*}$ \\
\hline UR2 & -5.99 & -2.54 & $0.002^{*}$ \\
\hline UR3 & -8.62 & -4.53 & $0.011^{*}$ \\
\hline UL1 & -4.66 & -2.68 & $0.003^{*}$ \\
\hline UL2 & -5.31 & -6.39 & $0.05^{*}$ \\
\hline UL3 & -5.8 & -7.0 & $0.0145^{*}$ \\
\hline
\end{tabular}

\section{DISCUSSION}

All maxillary anterior teeth showed apical root resorption with subsequent decrease in root surface area. In the laser group the average amount of root resorption was $1.16 \mathrm{~mm}$ of root shortening. In the control group, the average amount of root shortening was 1.31. This coincides with Lund et al who reported $90.2 \%$ of maxillary central incisors, $86.6 \%$ of maxillary lateral incisors and $76.8 \%$ of maxillary canines showing apical root resorption in 6 months only from baseline. ${ }^{(36)}$ The amount of root resorption is in agreement with previous reports. McFadden et al ${ }^{(25)}$ 
Egyptian

Orthodontic Journal

recorded average root resorption as $1.8 \mathrm{~mm}$. Linge and Linge ${ }^{(37)}$ reported $1.5 \mathrm{~mm}$. Mirabella and Artun $^{(33)}$ recorded an average of $0.94 \mathrm{~mm}$ of root resorption.

The decrease in root surface area was recorded in all teeth. The average decrease in root area was $4.3 \mathrm{~mm}^{2}$ in the laser group and $6 \mathrm{~mm}^{2}$ in the control. Similar amounts of decrease in root area were recorded in previous study. However significant difference was found, probably due to larger number of teeth studied. ${ }^{(38)}$

From the total number of examined teeth (60 lased and 60 control, $\mathrm{n}=120$ ), 12 showed root resorption more than $2 \mathrm{~mm}$ with percentage of $10 \%$ of total examined teeth. Only 5 teeth showed root resorption between a 3 and $3.5 \mathrm{~mm}$ with percentage $5 \%$ of total examined teeth. This is in agreement with previous report who detected $8 \%$ of incisors showing more than $3 \mathrm{~mm}$ resorption in 12 months of treatment. ${ }^{(39)}$

The absolute change in RL between the two groups showed significant difference in UR1, UR2 and UR3. Also, there was a significant difference in absolute change in RA in all teeth between the two groups. The control group showed relatively higher decrease in both RL and RA compared to laser group with the exception of UL2 and UL3 (both RL and RA) which can be attributed to individual variations

The surprising results of root resorption affecting all teeth could be explained by the accuracy of CBCT to quantify little amounts of root shortening. Previous radiographic methods of root resorption detection could have underestimated the amount of root resorption. ${ }^{(40)}$

En masse retraction of anterior teeth may have increased the chance of root resorption. Previous study reported an increased chance of root resorption with en masse retraction. ${ }^{(41)}$ Also the selection of cases with severe overjet may have increased the chance of root resorption due increased amount of incisors retraction. The percentage of root loss ranged from 6 to $12 \%$ of root length with no significant difference between two groups. This amount is less than reported previously (16 to $20 \%){ }^{(41)}$ 
Egyptian

Orthodontic Journal

The apical root resorption of the maxillary lateral incisors was greater than that of the maxillary central incisors and canines in both groups, which agrees with belief of higher susceptibility of lateral incisors to root resorption. ${ }^{33,34)}$

\section{CONCLUSION}

The risk of orthodontically induced root resorption exists for every patient undergoing orthodontic treatment. This recorded root resorption does not impose the risk of tooth loss or affects the longevity of the tooth. All patients or guardians of minors need to be informed of the chance root resorption occurrence. Within the limitations of this study, the low level laser didn't affect the amount of root resorption.

\section{REFERENCES}

1. Fink DF, Smith RJ. The duration of orthodontic treatment. Am J Orthod Dentofac Orthop. 1992; 102:45-51.

2. Bishara SE, Ostby AW. White spots lesions: formation, prevention, and treatment. Semin Orthod. 2008; 14:174-182.

3. Segal GR, Schiffman PH, Tuncay OC. Meta analysis of the treatment related factors of external apical root resrption. Orthod Craniofac Res. 2004; 7:71-78.

4. Royko A, Denes Z, Razouk G. The relationship between the length of orthodontic treatment and patient compliance. Fogorv Sz.1999; 92:79-86.

5. Kole H. Surgical operations on the alveolar ridge to correct occlusal abnormalities. Oral Surg Oral Med Oral Path. 1959:12(5):515-29.

6. Wilcko WM, Wilcko T, Bouquot JE, Ferguson DJ. Rapid orthodontics with alveolar reshaping: two case reports of decrowding. Int J Periodontics Restorative Dent. 2001; 21(1):9-19.

7. Davidovitch Z, Finkelson MD, Steigman S, Shanfeld JL, Montgomery PC, Korostoff E. Electric currents, bone remodeling, 
Egyptian

Orthodontic Journal

and orthodontic tooth movement. II. Increase in rate of tooth movement and periodontal cyclic nucleotide levels by combined force and electric current. Am J Orthod 1980; 77:33-47.

8. Stark TM, Sinclair PM. Effect of pulsed electromagnetic fields on orthodontic tooth movement. Am J Orthod Dentofac Orthop 1987; 91:91-104.

9. Yamasaki K, Shibata Y, Fukuhara T. The effect of prostaglandins on experimental tooth movement in monkeys (Macaca fuscata). J Dent Res. 1982; 61(12):1444-6.

10. Kawasaki K, Shimizu N. Effects of low-energy laser irradiation on bone remodeling during experimental tooth movements in rats. Lasers Surg Med 2000; 26:282-91.

11. Sun X, Zhu X, Xu C, Ye N, Zhu H. Effects of low energy laser on tooth movement and remodeling of alveolar bone in rabbits. Hua Xi Kou Qiang Yi Xue Za Zhi 2001; 19:290-3.

12. Cruz DR, Kohara EK, Ribeiro MS, Wetter NU. Effects of low intensity laser therapy on the orthodontic velocity of human teeth: A Preliminary study. Lasers Surg Med 2004; 35:117-20.

13. Goulart CS, Nouer PR, Mouramartins L, Garbin IU, de Fátima Zanirato Lizarelli R. Photoradiation and orthodontic movement: experimental study with canines. Photomed Laser Surg 2006; 24:192-6.

14. Youssef M, Askhar S, Hamade E, Gutknecht N, Lampert F, Mir M. The effect of low-level laser therapy during orthodontic movement: a preliminary study. Laser Med Sci 2007; 123:27-33.

15. Yoshida T, Yamaguchi M, Utsunomiya T, Kato M, Arai Y, Kaneda T, Yamamoto H, Kasai K. Low-energy laser irradiation accelerates the velocity of tooth movement via stimulation of the alveolar bone remodeling. Orthod Craniofac Res 2009; 12(4):289-98. 
Egyptian

Orthodontic Journal

16. Habib FAL, Gama SKC, Ramalho LMP, Cangussu MCT, Santos Neto FP, Lacerda JA et al. Laser-induced alveolar bone changes during orthodontic movement: A histologic study on rodents. Photomed Laser Surg 2010; 28:823-30.

17. Sousa MVS, Scanavini MA, Sannomiya EK, Velasco LG, Angelieri F. Influence of low level laser on the speed of orthodontic treatment. Photomed Laser Surg 2011; 29:191-96.

18. Doshi-Mehta G, Bhad-Patil WA. Efficacy of low intensity laser therapy in reducing treatment time and orthodontic pain: A clinical investigation. Am J orthod Dentofac Orthop 2012; 141:289-97.

19. Limoanichkul W, Godfrey K, Ssrisuk N, Rattanayatikul C. Effects of low-level laser therapy on the rate of orthodontic tooth movement. Orthod Craniofacial Res 2006; 9:38-33.

20. Habib FAL, Gama SKC, Ramalho LMP, Cangussu MCT, Santos Neto FP, Lacerda JA et al. Laser-induced alveolar bone changes during orthodontic movement: A histologic study on rodents. Photomed Laser Surg 2010; 28:823-30.

21. Seifi M, Shafeei HA, Daneshdoost S, Mir M. Effects of two types of low-level laser wave lengths (850 and $630 \mathrm{~nm})$ on the orthodontic tooth movements in rabbits. Lasers Med Sci. 2007; 22(4):261-4.

22. Hartsfield JK Jr, Everett ET, Al-Qawasmi RA. Genetic factors in external apical root resorption and orthodontic treatment. Crit Rev Oral Biol Med 2004; 15:115-22.

23. Harris EF, Kineret SE, Tolley EA. A heritable component for external apical root resorption in patient treated orthodontically. Am J Orthod Dentofac Orthop 1997, 111:301-309.

24. Brezniak and Wasserstein, Root resorption after treatment Part 2: Literature Review. Am J Orthod Dentofac Orthop 2003; 138 - 146.

25. McFadden WM,Engstrom H, Anholm JM. A study of the relationship between incisor intrusion and root shortening. Am J Orthod Dentofac Orthop 1989;96:390-96. 
Egyptian

Orthodontic Journal

26. Remington DN, Joondeph DR, Artun J. Long term evaluation of root resorption occurring during orthodontic treatment. Am J Orthod Dentofac Orthop 1989; 96:43-46.

27. Taithongchai R, Sookorn C, Schneider BJ. Facial and dentoalveolar structure and the prediction of apical root shortening. Am J Orthod Dentofac Orthop 1996; 110:296-302.

28. Phillips JR.Apical root resorption under orthodontic therapy. Angle Orthod 1955; 25:1-22.

29. Kurol J,Owman-Moll P,Lundgren D. Time related root resorption after application of a controlled continuous orthodontic force. Am J Orthod Dentofac Orthop 1996; 110:303-10.

30. Alexander SA. Levels of root resorption associated with continuous and sectional arch mechanics. Am J Orthod Dentofac Orthop 1996; 109:76-84.

31. Cotspoulos G, Nanda R. An evaluation of root resorption incident to orthodontic intrusion. Am J Orthod Dentofac Orthop 1996; 110:321-24.

32. Blake M, Woodside DG, Pharoah MJ. A radiographic comparison of apical root resorption after orthodontic treatment with the edgewise and speed appliances. Am J Orthod Dentofac Orthop 1995; 108:76-84.

33. Mirabella AD,Artun J. Risk factors for apical root resorption of maxillary anterior teeth in adult orthodontic patients. Am J Orthod Dentofac Orthop 1995; 108:48-55.

34. Sameshima GT, Sinclair PM. Predicting and preventing root resorption:Part I. Diagnostic factors. Am J Orthod Dentofac Orthop 2001; 119;505-10.

35. Taner T, Ciger S, Sencift Y. Evaluation of apical root resorption following extraction therapy in subjects with class I and Class II malocclusions. Eur J Orthod 1999; 21:491-96.

36. Lund H, Grondahl K, Hansen K, Grondahl HG. Apical root resorption during orthodontic treatment: A prospective study using cone beam CT. Angle Orthod 0000; 00:1-8. 
Egyptian

Orthodontic Journal

37. Linge L, Linge BO. Patient characteristics and treatment variables associated with apical root resorption with apical root resorption during orthodontic treatment. Am J Orthod Dentofac Orthop 1991;99:35-43.

38. Ahn HW, Moon SC, Baek SH. Morphometric evaluation of changes in the alveolar bone and roots of maxillary anterior teeth before and after en masse retraction using cone-beam computed tomography. Angle Orthod 2013;83:212-221.

39. Artun J, Smale I, Behbehani F, Doppel D, Van't Hof M, Kuijpers-Jagtman AM. Apical root resorption six and 12 months after initiation of fixed orthodontic appliance therapy. Angle Orthod 2005; 75:919-26.

40. Dudic A, Giannopoulou C, Leuzinger M, Kiliaridis S. Detection of apical root resorption after orthodontic treatment by using panoramic radiography and cone-beam computed tomography of super-high resolution. Am J Orthod Dentofac Orthop. 2009; 135:434-437.

41. Liou EJW, Chang PMH. Apical root resorption in orthodontic patients with en-masse maxillary anterior retraction and intrusion with miniscrews. Am J Orthod Dentofac Orthop 2010; 137:207-12. 